\title{
SUBJETIVIDADE E COISIFICAÇÃO: UM ESTUDO INTRODUTÓRIO
}

\author{
SUBJECTIVITY AND OBJECTIFICATION: \\ AN INTRODUCTORY ANALYSIS \\ SUBJECTIVITÉ ET CHOSIFICATION HUMAINE: \\ UNE ÉTUDE INTRODUCTIVE \\ SUBJETIVIDAD Y COSIFICACIÓN HUMANA: \\ UN ESTUDIO INTRODUCTORIO
}

\author{
Luciene Maria Bastos*
}

\begin{abstract}
RESUMO
O contexto histórico da modernidade tece novas dimensōes da constituição do homem e da sociedade. O momento traz em seu bojo a marca emblemática da elevaçāo do sujeito, o qual tende a potencializar sua possibilidade de emancipação e esclarecimento. Entretanto, a promessa iluminista de autonomia não se cumpre, o movimento de esclarecimento redunda em alienação da consciência humana, concretizando uma subjetividade regredida e, por isso, fragilizada. Consolida-se um sujeito da razão individual que tende à irreflexão e ao automatismo, a um estado de res, de coisa. Este trabalho visa uma análise preliminar dos elementos que possibilitam tal coisificação da subjetividade.
\end{abstract}

Palavras-chave: Subjetividade. Coisificação. Consciência.

* Mestre em Educação pela Universidade Federal de Goiás. Professora de disciplinas do Curso de Pedagogia da Universidade Estadual de Goiás de Campos Belos (lucienemeb@yahoo.com.br). 


\section{INTRODUÇÃO: BREVE CONTEXTUALIZAÇÃO}

A cisão cartesiana entre sujeito e objeto, res cogitans e res extensa, simbolicamente inaugura a modernidade, revolucionando o modo de ser, de pensar e de explicar o mundo. Para Ianni (1995), modernidade "diz respeito a um modo de agir, pensar e imaginar, ou seja, a um estado de espírito envolvendo dilemas e horizontes filosóficos, científicos e artísticos" (p. 90). A modernidade surge como promessa de um novo mundo, agora pleno de condiçôes para a efetivação do avanço da humanidade em todos os sentidos: social, político, econômico, cultural e ético.

Descartes (1962), ao instituir a razão como possibilidade de todo homem, retira-a do plano divino e a circunscreve no âmbito humano, iniciando, assim, o movimento de desencantamento e humanização do mundo. O Iluminismo mantém certos preceitos da razão cartesiana, mas vai além, imbuindo a razão de uma função transformadora, aperfeiçoadora e libertadora. Os iluministas "acreditavam que a sociedade humana e o homem individualmente podiam ser aperfeiçoados pela mesma aplicação da razão, e que estavam destinados a seu aperfeiçoamento na história” (HOBSBAWM, 2004a, p. 326).

A promessa iluminista de emancipação baseava-se numa apaixonada crença no progresso advindo do conhecimento técnico, o qual redundaria no bem-estar da humanidade. Sua força derivava da ciência, sobretudo da matemática e da física, que haviam revolucionado o século XVII. Assim, no decorrer do século XVIII, a convicção no progresso do conhecimento humano por meio do controle sobre a natureza fez da ciência, especialmente a ciência positiva, o método por excelência de aferição da verdade, isto é, do conhecimento. O positivismo é uma ciência cuja gênese ocorre num contexto de secularização do conhecimento. Pode-se afirmar, a partir da reflexão de Horkheimer e Adorno (1973) sobre a sociologia, que também a ciência positiva: "Nasceu da vontade de emancipar o conhecimento dos credos religiosos e da especulação metafísica. Mediante uma rigorosa fidelidade aos fatos, também se esperava atingir neste campo a objetividade de que eram modelo as ciências naturais, empíricas de um lado e matemáticas por outro" (p. 11). Teoricamente, com o desenvolvimento da ciência o progresso humano se efetivaria simultaneamente, ou seja, a liberdade adquiriria materialidade.

A idéia de progresso é a pedra angular do "edifício" da sociedade burguesa iluminista, a qual se fundamenta no capitalismo, na ciência e na razão. Em tese, uma sociedade baseada em tais pressupostos deveria "não somente criar um mundo de plena distribuição material, mas também de crescente esclarecimento, razão e oportunidade humana, de avanço das ciências e das artes, em suma, um mundo de contínuo progresso material e moral" (HOBSBAWM, 2004b, p. 19). Conforme essa visão, o progresso era tão natural quanto o capitalismo. O progresso da produção estava intimamente ligado ao progresso das artes, das ciências e da civilização, ou seja, da cultura em geral. Hobsbawm enfatiza que as transformaçōes sociais, econômicas, políticas e culturais advindas da "dupla revolução" [revolução francesa e industrial] demonstraram, incontestavelmente, o triunfo do 
capitalismo liberal burguês. A primazia não foi da liberdade e da igualdade em geral, mas "da classe média ou da sociedade 'burguesa' liberal” (2004a, p. 16).

O movimento das "luzes" traz em seu bojo a promessa do surgimento de um indivíduo emancipado, de pensamento secular e livre. Originariamente, o Iluminismo configurava-se, segundo Horkheimer e Adorno (1985, p. 19), como promessa de esclarecimento, com o fim de "livrar os homens do medo e de investi-los na posição de senhores"; a meta era "dissolver os mitos e substituir a imaginação pelo saber". No sentido mais amplo, o pensamento tem perseguido o esclarecimento com a finalidade de desmistificar o mundo, ou seja, superar a magia e a superstição mediante o uso da razão, isto é, pelo conhecimento, pela educação - no sentido amplo de cultura.

Como crítica radical da racionalidade científica e pragmática, e traduzindo a desilusão intelectual quanto ao não-cumprimento da promessa iluminista, surge a Escola de Frankfurt em 1924. Sob a influência das análises de Marx e de sua crítica à economia política burguesa, a teoria crítica da Escola de Frankfurt denuncia a convergência dos conceitos em seus opostos: a racionalidade em irracionalidade, a desmistificação em mistificação, o progresso em regresso. Esses autores se dedicaram a demonstrar que a racionalidade da dominação da natureza para fins lucrativos, isto é, a ciência e a técnica a serviço do capital, engendra a "ditadura da produção" (MATOS, 1993, p. 7).

Semelhante ditadura passa a estruturar e direcionar a vida humana. São configurados processos tão sutis que se instalam na consciência do homem, que, aparentemente, este perde o status de sujeito da história. Por conseguinte, o homem tende a ser convertido em mero consumidor de produtos e idéias que a grande indústria da cultura lhe imputa como necessidades vitais, num processo de alienação de sua consciência.

\section{ALIENAÇÃO DA CONSCIÊNCIA}

O homem nasce carente e, na intenção de satisfazer necessidades como comer, beber e abrigar-se, cria possibilidades de existência por meio de sua ação vital: o trabalho. As carências humanas levam o homem a exteriorizar seu pensamento, o que se configura como uma necessidade natural. Segundo Marx (1989), o objeto é unicamente a autoconsciência objetivada, isto é, o ato de o homem exteriorizar seu pensamento na realidade. À medida que cria sua existência, cria também o mundo ao seu redor. Nessa medida, o trabalho é condição fundamental na formação da subjetividade humana, processo que afirma e reafirma sua condição de ser humano, frente a si mesmo, à natureza e aos outros homens.

O trabalho é condição ontológica do homem, isto é, consiste em condição de sua existência. $\mathrm{O}$ produto do trabalho é expressão da consciência humana, representa sua objetivação no mundo material, ou seja, na objetividade. É o momento em que o homem vê a si mesmo no mundo, constituindo-se em fator de reconhecimento de sua 
humanidade e de sua liberdade. É o trabalho que constitui o homem em sentido universal e histórico (MARX, 1983). Assim, mediante sua ação no mundo, o homem se diferencia da natureza e nega sua animalidade. Nesse movimento, a realidade externa, o outro social, é negada como pura exterioridade e passa a constituir a consciência humana. Desse modo, o trabalho expressa, e é expressão, da relação de dependência recíproca entre indivíduo e sociedade, pois, à medida que o homem se exterioriza, isto é, se objetiva no mundo, é erigida a realidade social, a qual passa a compor o indivíduo. Nesse sentido, a consciência é fruto do trabalho expresso nas relaçôes sociais, numa relação dialética entre sujeito e sociedade determinante para a construção da subjetividade.

Nessa perspectiva, refletir sobre a subjetividade pressupõe analisá-la em relação às transformações objetivas históricas do modo de produção da vida humana. Nessa relação, o advento do capitalismo, concomitante à emergência da sociedade burguesa a sociedade moderna -, generaliza a divisão social do trabalho em material e intelectual. O modo de produção capitalista consolida-se como sistema produtor de mercadorias, cujos elementos constitutivos, basicamente, são a intensificação do trabalho parcelar e a fragmentação das funções. À medida que se expande a separação entre elaboração e execução no processo de trabalho, ocorre o alheamento do homem de sua atividade ontológica, configurando-se a vigência do trabalho alienado e estranhado. A constituição do homem passa a se subordinar às relações materiais de produção fragmentadas e opacas, que originam um processo de velamento e obscurecimento da consciência individual e coletiva do sujeito. À medida que as características impregnadas nos produtos do trabalho humano assumem a forma de objetividade da mercadoria, como propriedades naturais sociais, se expressa a fetichização do trabalho humano. Nesse processo, a relação do trabalhador com o trabalho, seu dispêndio de forças, aparece como uma relação exterior entre objetos. Nas palavras de Marx, o fetiche:

Não é nada mais que determinada relação social entre os próprios homens que para eles assume a forma fantasmagórica de uma relação entre coisas. [...] Assim, no mundo das mercadorias, acontece com os produtos da mão humana. Isso eu chamo o fetichismo que adere aos produtos de trabalho, tão logo são produzidos como mercadorias, e que, por isso, é inseparável da produção de mercadorias (MARX, 1983, p. 71).

O caráter fetichista do mundo das mercadorias provém do caráter social peculiar do trabalho que produz mercadorias. Em outros termos, é inerente às condiçôes do trabalho sob o capitalismo. O caráter fetichista presente nas mercadorias transforma as relações estabelecidas entre os homens em relações entre "coisas" que assumem uma existência independente. Nesse processo, os homens se coisificam em relaçōes reificadas à medida que as coisas (mercadorias) parecem adquirir vida nas relações sociais.

As relações humanas se perdem e passam a ser mediadas pelas leis do mercado. O que existe é a relação entre mercadorias, coisas. O fetiche e a coisificação atingem o indivíduo para além da objetividade, pois atuam em sua subjetividade. Alienado de sua consciência, 
coisificado, o indivíduo fica impossibilitado de perceber a lógica do mercado que vela a realidade de sua produção. Assim, Marx desvela que a mercadoria é, no limite, essencialmente fetiche, e que esta é uma forma ilusória necessária ao funcionamento do sistema capitalista, mantido por meio da relação de produção e consumo. A mercadoria aparece aí desvinculada, de certa forma, das necessidades humanas naturais, deixando de ser consumida, prioritariamente, por seu valor de uso, mas, essencialmente, sendo consumida como mercadoria ou como uma necessidade socialmente criada.

Para Horkheimer e Adorno (1985), o desencantamento, promessa do iluminismo, se converte em reencantamento. A racionalidade, que deveria se afastar do mito, é encantada pelo fetiche e ao mito retorna. $\mathrm{O}$ indivíduo, constituído por um processo de socialização empobrecido, numa cultura administrada pelos interesses mercantis, o qual enfraquece o desenvolvimento das qualidades humanas morais, se apega à ilusão de satisfação imediata. Os produtos do trabalho, que se constituíam em meios para alcançar a humanização como fim, assumem a totalidade, quando, na verdade, em sua essência, representam apenas a parte, a particularidade, para se alcançar a experiência humana. Assim, o indivíduo permanece preso ao particular, vivendo as relações humanas de individuação somente como experiência individualizante. A individuação é entendida como processo de socialização dos valores, crenças e comportamentos que permitem a construção da individualidade do homem - mediante a transmissão, elaboração, significação e criação da cultura - e, consequentemente, sua constituição como sujeito social.

Ao longo dos séculos, o modo capitalista de produção tem modificado sua estrutura sob o ideário da liberdade e da autonomia humanas. Nesse sentido, atualmente, há uma supervalorização do indivíduo, tornando a subjetividade um dos fatores mais visados na contemporaneidade. A questão é em que sentido se pauta semelhante valorização, pois, apesar de tantas promessas e condições para a autonomia, o que a realidade expressa é um indivíduo progressivamente aprisionado ao mercado econômico, espaço em que as reorganizações do capital sobre o trabalho concorrem para o atrofiamento da subjetividade autônoma.

O trabalho apenas como codificação de técnicas e a intrumentalização do pensamento subsidiam a dominação da subjetividade por mecanismos econômicos, culturais e ideológicos do capitalismo. Segundo Horkheimer e Adorno (1985): "A maldição do progresso irrefreável é a irrefreável regressão" (p. 46). O aprisionamento do trabalho à técnica exclui a liberdade e a experiência produtora do reconhecimento da universalidade. A resignação do pensamento à codificação de técnicas significa o empobrecimento deste e da experiência, caracterizando a regressão humana.

Quanto mais complicada e mais refinada a aparelhagem social, econômica e científica, para cujo manejo o corpo já há muito foi ajustado pelo sistema de produção, tanto mais empobrecidas as vivências de que ele é capaz. Graças aos modos de trabalho racionalizados, a eliminação das qualidades e sua conversão em funçôes transferem-se da ciência para o mundo da experiência dos povos e tende a assemelhá-lo de novo ao mundo dos anfíbios. A regressão das massas, de 
que hoje se fala, nada mais é senão a incapacidade de poder ouvir o imediato com os próprios ouvidos, de poder tocar o intocado com as próprias mãos: a nova forma de ofuscamento que vem substituir as formas míticas (HORKHEIMER; ADORNO, 1985, p. 47).

A substituição, nas objetivações humanas, do reconhecimento pela negação, pela fragmentação e pelo isolamento, resulta no embrutecimento humano. Nessa medida, o processo de individuação do homem, a construção do indivíduo como ser consciente de sua própria individualidade, passa a ser constituído pela individualização exacerbada. Nesse caso, a individualidade perde o sentido de liberdade e força individual, dissolvendo-se em "uma síntese dos interesses materiais do indivíduo" (HORKHEIMER, 2000, p. 140). O resultado desse processo é a fetichização da subjetividade, em que o indivíduo se torna um ser vazio, acrítico, coisificado, o que ocorre justamente em virtude de lhe faltar o reconhecimento de si mesmo como sujeito, resultando que seu espírito tende a ser regido pela razão formalizada. Em virtude de a sociedade ser uma totalidade, a fetichização da subjetividade afeta os diversos grupos sociais, o trabalhador não menos do que o capitalista.

Semelhante racionalidade se mantém por meio de um grande aparato ideológico que materializa a ilusão de que os problemas sociais serão resolvidos pelo progresso tecnológico, negando o real. Para Adorno (1993), a ideologia não se reduz a um sistema de idéias ou representações culturais, não é uma característica de tal ou qual consciência social, mas, de forma bem específica, é um processo responsável pela formação da "consciência social".

A ideologia apresenta a experiência social como realidade imediata, quando na verdade são experiências mediadas por um processo de produção. A eficiência da ideologia reside justamente em sua capacidade em vedar, camuflar a atividade social mediante o impedimento da reflexão sobre o modo como a realidade fora produzida. Assim, ela produz uma falsa experiência social, falsa precisamente por ocultar sua verdade.

Contundentemente, é essa falsa experiência que permite a reprodução da realidade social corporificada na sociedade burguesa capitalista, por meio de homens que a vivenciam cotidianamente. O primado da imediatez é garantido pelo princípio imanente do capitalismo, a saber, o "princípio de equivalência", sob o qual tudo e todos são intercambiáveis indiferentemente.

A ideologia cria a ilusão de que no mercado há uma livre troca de equivalentes. Assim, consequentemente, obscurece a compreensão das reais condições da existência social, vela a consciência da exploração e da dominação. Cria uma aparência ilusória.

Segundo Crochik (2003), as ilusões são fornecidas, na atualidade, pela ideologia tecnológica, a qual é reproduzida de forma vigorosa, mas não unicamente, pelos meios de comunicação em massa, os quais são apropriados pela indústria cultural. 


\section{A INDÚSTRIA CULTURAL}

A afirmação de Horkheimer e Adorno (1985) "a cultura contemporânea confere a tudo um ar de semelhança” (p. 113) já explicita o teor de sua discussão acerca da indústria cultural, termo cunhado pelos autores em 1947, quando da publicação da obra Dialética do esclarecimento. Segundo as palavras de Adorno:

Em nossos esboços tratava-se do problema da cultura de massa. Abandonamos essa última expressão para substituí-la por "indústria cultural", a fim de excluir de antemão a interpretação que agrada aos advogados da coisa; estes pretendem, com efeito, que se trata de algo como uma cultura surgindo espontaneamente das próprias massas [...] atribui-lhes nova qualidade [...] produtos adaptados ao consumo de massas e que em grande medida determinam esse consumo (ADORNO, 1993, p. 92).

Os produtos da indústria cultural doutrinam e manipulam a consciência do indivíduo, uma vez que trazem consigo atitudes e hábitos prescritos, certas reações intelectuais e emocionais que prendem os consumidores mais ou menos agradavelmente aos produtos e, por meio destes, ao todo social. A identificação com as mercadorias adquire uma dimensão quase absoluta na vida dos indivíduos, em que:

As criaturas se reconhecem em suas mercadorias; encontram sua alma em seu automóvel, hi-fi, casa em patamares, utensílios de cozinha. O próprio mecanismo que ata o indivíduo à sua sociedade mudou, e o controle social está ancorado nas novas necessidades que ela produziu (MARCUSE, 1973, p. 30).

Todavia, esse é um falso reconhecimento, pois de fato o que ocorre é uma cega identificação, mediada pelo fetiche, com as qualidades humanas incorporadas pela imagem do produto. $\mathrm{O}$ suposto reconhecimento em mercadorias expressa a racionalidade de uma sociedade baseada na aparência. $O$ falso reconhecimento é expressão de uma pseudoliberdade, pois, independentemente do quanto o indivíduo se encontre na satisfação de necessidades produzidas pela indústria, o que é fortalecido pelas condiçõos de sua existência, esses são produtos de uma sociedade cujo objetivo é o controle social. É o falso reconhecimento e a pseudoliberdade que impulsionam a indústria cultural. Seu caráter sedutor fetichista está justamente na ilusão em associar modelos de juventude, de beleza e de saúde aos objetos de consumo, como se tais atributos pertencessem "naturalmente" aos objetos, dando a ilusão da aquisição de tais atributos (ideais) por ocasião da compra. Essa intensa estimulação dos ideais provoca a identificação/reconhecimento por parte dos consumidores, que passam a consumir o que a mercadoria encerra como ideal.

Nesse processo, a subjetividade figura como subsunção aos modelos de comportamento insuflados pela indústria cultural, em que as mais íntimas reações do indivíduo são reificadas:

As mais íntimas reaçôes das pessoas estão tão completamente reificadas para elas próprias que a idéia de algo peculiar a elas só perdura na mais extrema abstração: personality significa para elas pouco mais do que possuir dentes deslumbrantemente brancos e estar livres do suor nas 
axilas e das emoçōes. Eis aí o triunfo da publicidade na indústria cultural, a mimese compulsiva dos consumidores, pela qual se identificam às mercadorias culturais que eles, ao mesmo tempo, decifram muito bem (HORKHEIMER; ADORNO, 1985, p. 156, grifos meus).

A identificação com o produto ocorre pela elevação de seu suporte simbólico à medida que "as imagens" criadas no indivíduo o levam a identificar-se, não com o produto em sua materialidade, mas com o ideal de felicidade e de status ali implícitos. Em última instância, o objeto, a mercadoria, passa a ser, para o indivíduo, a fonte de referência e identidade.

Em grande medida, a adesão à indústria cultural é promovida pela ilusão de realização pessoal, em que a subjetividade, alienada de sua essência e constituída de forma fragmentada, se conforma aos valores inculcados, pois não se diferencia da realidade imposta; antes, procura a ela se mesclar. Os processos de alienação e fragmentação da subjetividade são intensamente ampliados com a incorporação de novas tecnologias. A relação do indivíduo com as inovações tecnológicas e informáticas cria o suposto de que a cultura atual é baseada na diferença, e, teoricamente, propicia maior liberdade ao sujeito.

À época da chamada "cultura de massas", momento da análise dos autores frankfurtianos, a indústria cultural agia por meio da massificação da produção em série, promovendo "a disseminação de bens padronizados para a satisfação de necessidades iguais" (HORKHEIMER; ADORNO, 1985, p. 114). A indústria cultural atualmente se promove exaltando a diferença. Todavia, tal exaltação é ideológica, pois vela que, em verdade, a diferença ainda é sacrificada.

A exaltação de uma cultura baseada nas "diferenças" se justifica pela atual fase da produção capitalista, a qual é baseada em produtos "personalizados", o que evoca a idéia de "individualidade" e "autonomia" subjacentes a tal produção. Entretanto, Adorno (1993) demonstrou que tal aclamação é uma falácia, pois, de fato, trata-se apenas de uma "estilização" dentro da produção:

A estilização [...] é apenas um aspecto da estandartização. Concentração e controle, em nossa cultura, escondem-se em sua própria manifestação. Não camuflados, eles provocariam resistências. Por isso, precisa ser mantida a ilusão e, em certa medida, até a realidade de uma realização individual (ADORNO, 1993, p. 123).

A indústria cultural, já nos primórdios da época moderna e agora mais intensamente, promove a ilusão de liberdade de escolha, de que vende produtos diferenciados para cada tipo de pessoa, e o indivíduo singular tem a impressão de que a mercadoria foi produzida tendo em vista sua própria necessidade. $\mathrm{O}$ engano é que, em verdade, são distinções ilusórias que fazem parte da organização e classificação efetuadas pelo "esquematismo" da indústria cultural, cuja função é prover a quantificação e proclamá-la como personificação e diferenciação. Nesse caso:

Para todos algo está previsto; para que ninguém escape, as distinções são acentuadas e difundidas. O fornecimento ao público de uma hierarquia de qualidades serve apenas para uma 
quantificação ainda mais completa. Cada qual deve se comportar, como que espontaneamente, em conformidade com seu level, previamente caracterizado por certos sinais, e escolher a categoria dos produtos de massa fabricada para seu tipo. [...] $\mathrm{O}$ esquematismo do procedimento mostra-se no fato de que os produtos mecanicamente diferenciados acabam por se revelar sempre como a mesma coisa (HORKHEIMER; ADORNO, 1985, p. 116).

Assim, "gosto" e "livre escolha" são categorias que fazem parte do que Adorno denominou estilização, a qual nada mais é do que um aspecto da estandartização, isto é, a padronização. De fato, a estilização é um mecanismo para camuflar a estandartização e, ao mesmo tempo, ocultar que se trata, como antes, de controlar e não permitir a resistência. Dessa forma, o que são proclamados como produtos individuais, visando à realização pessoal, são, afinal, meramente mecanismos e estratégias da indústria cultural para ocultar, de forma sutil, a padronização. Referente a esse aspecto, na contemporaneidade há uma redimensionalização dessa produção dita "personalizada", em função da sofisticação tecnológica. Apesar de Adorno, já à sua época, refletir e denunciar tal engodo: "Cada produto apresenta-se como individual; a individualidade mesma contribui para o fortalecimento da ideologia, na medida em que se desperta a ilusão de que o que é coisificado e mediatizado é um refúgio de imediatismo e de vida" (ADORNO, 1993, p. 94). A exacerbação do consumo apela para o imaginário do consumidor, prometendo a realização dos seus desejos de forma "personalizada".

Nesse sentido, o processo de individuação do sujeito converte-se em uma pseudoindividuação, a qual tem por base a padronização do comportamento humano, ou seja, a indiferenciação em relação à realidade social. A essência de tal processo reside em que a subjetividade é dissolvida em sua dimensão crítica, restando apenas a adaptação ao real. Adorno afirma:

Por pseudo-individuação entendemos o envolvimento da produção cultural de massa com a auréola da livre-escolha ou do mercado aberto, na base da própria estandartização. [...] a pseudo-individuação, por sua vez, os mantém enquadrados [consumidores] fazendo-os esquecer que o que eles escutam já é sempre escutado por eles, "pré-digerido" (1993, p. 123).

Dessa forma, o que está na base da pseudo-individuação é uma suposta diferenciação do indivíduo, tendo em vista a escolha pretensamente "livre" de objetos de consumo, a qual já está previamente "digerida”, isto é, está de antemão estandartizada, padronizada. A pseudo-individuação transcende a padronização, se expressa numa identificação com o universal, com o poder social que o determina, cujo fundamento reside na constituição de subjetividades direcionadas à integração, à adaptação e ao consumo exacerbado, segundo as necessidades do sistema econômico. $\mathrm{O}$ indivíduo constitui-se num processo de pseudo-individuação porque não se diferencia nesse universo, antes se homogeneíza. Nesse sentido:

As particularidades do eu são mercadorias monopolizadas e socialmente condicionadas, que se fazem passar por algo de natural. Elas se reduzem ao bigode, ao sotaque francês, [...] são como impressões digitais em cédulas de identidade que, não fosse por elas, seriam rigorosamente 
iguais e nas quais a vida e a fisionomia de todos os indivíduos [...] se transformam, em face do poderio universal (HORKHEIMER; ADORNO, 1985, p. 145).

Assim, o processo de individuação não se realiza, antes é substituído pela mimese, pela imitação: os indivíduos seguem modelos confeccionados pela indústria cultural, via publicidade. $\mathrm{O}$ cerne da crítica frankfurtiana reside justamente nessa adesão acrítica dos sujeitos à lógica mercadológica, caracterizando em nova dimensão a administração da cultura e da sociedade. $\mathrm{O}$ vínculo entre os seres humanos tende a ocorrer tendo em vista interesses exteriores, meros “contatos sociais". Nesse âmbito, a proclamada autonomia do indivíduo se revela como indiferenciação, uma vez que os indivíduos não se diferenciam do social, apenas seguem padróes preestabelecidos.

A indústria cultural veicula, enfaticamente, ilusões de uma sociedade justa, democrática, livre, e, acima de tudo, feliz; ao mesmo tempo em que as possibilidades de realização "de felicidade, justiça, e liberdade são suprimidas exatamente pela negação das condições sociais que geram a infelicidade, a opressão e a injustiça" (CROCHIK, 2003, p. 18). A defesa de um determinado tipo de democracia, liberdade, cidadania, veiculada a aspectos econômicos não permite que a consciência do homem perceba que estas não são a democracia, a liberdade e a cidadania ideais.

A indústria cultural exerce o papel de portadora e mantenedora da ideologia dominante; assim, cumpre seu papel de falsificadora das relaçóes entre os homens e destes com a natureza. A ideologia presente na indústria cultural substitui a realização de valores humanos pela adaptação à realidade estabelecida, negando ao sujeito uma consciência social, reduzindo-a à consciência particular e alienada, expropriada de si. Nesse processo, segundo Adorno (1993), "a dominação sobre os seres humanos continua a ser exercida através do processo econômico" (p. 67), ou seja, a subjetividade humana ainda conforma-se ao fetichismo da mercadoria e à coisificação. $\mathrm{O}$ autor diz ainda:

Se a teoria da miséria crescente não foi demonstrada a la lettre, ela se confirmou, porém, no sentido não menos assustador de que a falta de liberdade, a dependência em relação a um instrumental que escapa à consciência daqueles que dele se utilizam, estende-se universalmente sobre os homens. A tão deplorada falta de maturidade das massas é apenas o reflexo do fato de que os homens continuam não sendo senhores autônomos de sua vida; tal como no mito, sua vida lhes ocorre como destino (ADORNO, 1993, p. 67).

Essa é a questão latente: a sociedade desenvolveu apenas as forças de produção, ou seja, modernizou os meios técnicos, criando, numa expressão de Adorno, um "véu tecnológico" sobre a sociedade e a ilusão de que uma sociedade emancipada já estaria realizada. Contudo, o cerne da questão é que o desenvolvimento das forças produtivas não se fez acompanhar do desenvolvimento das relações humanas de trabalho; contrariamente, as relações sociais se coisificaram numa progressiva desumanização, em que:

Os homens seguem sendo, o que, segundo a análise de Marx, eles eram por volta da metade do século do século XIX: apêndices da maquinaria, e não mais apenas literalmente trabalhadores, 
que têm de se conformar às características das máquinas a que servem, mas além deles, muitos mais, metaforicamente: obrigados até mesmo em suas mais íntimas emoções a se submeterem ao mecanismo social como portadores de papéis, tendo de se modelar sem reservas de acordo com ele (ADORNO, 1993, p. 68).

O fetiche da mercadoria alcança a cultura e as "mais íntimas emoções" do homem, não mais apenas na dimensão do trabalho, mas em todas as esferas da vida humana. A submissão à organização social é feita pela modelagem da subjetividade. Com a indústria cultural, a alienação e o fetiche alcançam a dimensão de coisificação da subjetividade de forma intensa, seu locus passa a ser o consciente e o inconsciente.

\section{ADMINISTRAÇÃO DO INCONSCIENTE}

Segundo Marcuse (1975), os processos de regressão sofridos pelo indivíduo, já à época da "sociedade de massa", são motivados pelo nível de desenvolvimento capitalista, que, cada vez mais, depende de uma produção ininterrupta e do consumo de produtos supérfluos, das novas e obsoletas invenções técnicas, assim como os meios de destruição. Por seu lado, o indivíduo "precisa" se adaptar a esses requisitos de um modo cada vez mais sutil. A adaptação e a aceitação de tal expansão capitalista dependem de uma forma mais refinada de manipulação, ultrapassando a consciência e chegando ao inconsciente do indivíduo, na administração de sua energia vital, a libido: "A administração científica das necessidades instintivas converteu-se, desde há muito, em fator vital na reprodução do sistema: a mercadoria que tem que ser comprada e usada traduz-se em objetos da libido" (MARCUSE, 1975, p. 14).

Segundo a análise marcuseana, a administração da libido, ou seja, da força que move os desejos mais primitivos do homem, é possível graças ao enfraquecimento do ego, que, expropriado de sua dimensão crítico-reflexiva, adere de forma mimética ao todo social.

Desde cedo os indivíduos são submetidos a mecanismos de socialização que os levam, de um lado, à aceitação, e, de outro lado, excluem qualquer resistência. O sistema social exige do indivíduo, para sua integração e pertencimento, o total abandono ao poder coletivo.

As massas desmoralizadas por uma vida submetida à coerção do sistema, e cujo único sinal de civilização são comportamentos inculcados à força e deixando transparecer sempre sua fúria e rebeldia latentes, devem ser compelidas à ordem pelo espetáculo de uma vida inexorável e da conduta exemplar das pessoas concernidas. [...] A postura que todos são forçados a assumir, para comprovar continuamente sua aptidão moral a integrar essa sociedade, faz lembrar aqueles rapazinhos que, ao serem recebidos na tribo sob as pancadas dos sacerdotes, movem-se em círculos com um sorriso estereotipado nos lábios. A vida no capitalismo tardio é um contínuo rito de iniciação. Todos têm que mostrar que se identificam integralmente com o poder de quem não cessam de receber pancadas (HORKHEIMER; ADORNO, 1985, p. 143-144). 
O debilitamento do ego ocorre, sobretudo, em razão de dois fatores: primeiramente, o indivíduo sofre um processo de socialização predominantemente extrafamiliar, mediado, sobremaneira, pelos meios de comunicação e sua racionalidade instrumental; em segundo lugar, o trabalho, elemento diferenciador e singularizador do ser humano, se transforma em fator de alienação, massificação e abstração. Assim, o indivíduo não constrói um ego forte, pois os elementos formadores da dimensão de negação, tragicidade, medo, dor, enfim, os constituintes da condição humana com seus embates e contradiçôes, se perdem na identificação com a falsa harmonia da realidade. Com essa fragilização do ego, o indivíduo passa a ser profundamente "invadido e debastado pela realidade tecnológica" (MARCUSE, 1973, p. 30). O que resulta, assim, numa redução fundamental no poder de arbítrio do ego, havendo a substituição dos processos reflexivos de discussão e julgamento por reaçôes "automáticas". O ego, assim fragilizado, fica à mercê da autoridade externa.

Entretanto, segundo Marcuse (1973), tal debilitamento é possível porque as "pulsōes libidinais" são redirecionadas conforme a lógica produtiva do sistema, o qual se utiliza do desejo humano de "gratificação", quer dizer, da busca de satisfação imediata não completamente extinta do "princípio do prazer". Dessa forma, os desejos inconscientes do homem são utilizados pelo sistema capitalista, via indústria cultural.

Segundo Freud (1996a), em O mal-estar da civilização, o homem nasce com pulsões (instintos) sexuais e agressivas, que, independente da realidade, buscam satisfação imediata. O que possibilita a vida em sociedade, ou seja, a civilização, a cultura, é a renúncia a tais pulsões. $\mathrm{O}$ desenvolvimento social está, assim, condicionado às restrições a que o indivíduo se submete. Nessas restriçōes aos impulsos, o indivíduo é levado à sublimação, ou seja, "a deslocar as condiçōes de sua satisfação, a conduzi-la para outros caminhos" (FREUD, 1996a, p. 103) que possibilitem a cultura (como atividades psíquicas superiores, científicas, artísticas ou ideológicas). Mediante a sublimação, o indivíduo é levado a abdicar de sua motivação inicial de obter prazer imediato, momento esse que expressa sua subsunção ao "princípio do prazer" (FREUD, 1996b). Sob esse princípio, o prazer deve ser alcançado de forma imediata, sem considerar a realidade externa; ao mesmo tempo em que o prazer é buscado, o desprazer deve ser afastado. No decorrer do seu desenvolvimento, o indivíduo adquire progressivamente a capacidade de adiar a "gratificação", ou seja, a satisfação, até momentos e circunstâncias mais adequados. Em tal capacidade de adiamento, sob a influência dos instintos de autopreservação, fundamenta-se, segundo Freud (1996c), a substituição do "princípio de prazer" pelo "princípio de realidade", o que demonstra o amadurecimento e diferenciação do ego.

Contudo, o "princípio do prazer" não abandona a intenção de fundamentalmente obter prazer. A busca por prazer persiste como uma tendência, pois, como afirmou Freud, é ele "que decide o propósito da vida", é este princípio que "domina o funcionamento do aparelho psíquico" (1996a, p. 84). 
Dessa forma, segundo a perspectiva freudiana, há um permanente conflito entre demandas pulsionais (instintivas) e as regulaçōes da cultura sobre os homens, uma vez que o perigo da agressividade deve ser constantemente restringido. $\mathrm{O}$ antagonismo entre a constituição do indivíduo e da cultura é recriado cada vez que uma pessoa se insere na sociedade. Assim, o indivíduo se desenvolve confrontando-se em sua vida cotidiana com o dilema da impossibilidade da satisfação pulsional. Ao longo da sua vida, o indivíduo persegue o objetivo de alcançar a felicidade, apesar de a completude, ou seja, a satisfação total, não lhe ser possível, o que gera o sentimento de mal-estar oriundo da restrição da pulsão (instinto). Portanto, o sujeito possui uma tendência a buscar a gratificação, a satisfação direta e imediata de suas necessidades e desejos - esse dilema é justamente o elemento subjetivo utilizado pela indústria cultural para aprisionar os consumidores nas malhas do consumo.

A promessa de realização dos desejos humanos por meio da aquisição crescente de bens e serviços oferecidos pela indústria cultural e a "liberação" dos controles societários em relação ao sexo concorrem, inequivocamente, para a anulação do conflito que tente subverter essa ordem tão "confortável". Sob esse contexto, segundo Marcuse (1973), a gratificação assume a forma de "dessublimação". Nesta, inversamente à sublimação, a satisfação mediada é substituída por satisfação imediata. Nessa situação, o "princípio do prazer" absorve o "princípio da realidade", numa nova reorientação das "pulsões libidinais". Nesse contexto, a realidade tecnológica limita o alcance da sublimação e também reduz sua necessidade. Assim, segundo Marcuse, o indivíduo deve se adaptar a um mundo que parece não exigir a negação de suas necessidades mais íntimas - um mundo que não parece essencialmente hostil. "O organismo está sendo assim precondicionado para a aceitação espontânea do que é oferecido” (MARCUSE, 1973, p. 84). Desse modo, é proclamada maior liberdade, mas, na verdade, ocorre uma contração da liberdade, pois se enaltece o desenvolvimento das necessidades "instintivas".

A "liberdade" sexual conquistada pelas sociedades modernas, no limite, converteu o sexo em mercadoria altamente comercializável. Assim, a integração do sexo no trabalho e nas relações sociais, tornando-se mais suscetível de satisfação, significa uma satisfação, ao mesmo tempo, controlada e desenfreada. Desenfreada, pois é uma satisfação dissociada da moral, mas controlada pelos interesses da indústria do capital. Dessa forma, ocorre uma mobilização e, ao mesmo tempo, uma administração da libido, causando a adesão ao status quo pelo inconsciente:

Essa mobilização e administração da libido pode ser a responsável por muito da submissão voluntária, da ausência de terror, da harmonia preestabelecida entre necessidades individuais e desejos, propósitos e aspiraçôes socialmente necessários. A conquista tecnológica e política dos fatores transcendentes da existência humana, tão característica da civilização industrial desenvolvida, afirma-se aqui na esfera instintiva: satisfação de um modo que gera submissão e enfraquece a racionalidade do protesto (MARCUSE, 1973, p. 85). 
Gera-se, assim, uma "dessublimação ajustada", que enaltece e promove um prazer controlado. Marcuse (1973) acredita que a sublimação exige um alto grau de autonomia, uma vez que preserva a consciência das renúncias que a sociedade lhe infligiu, preservando a necessidade de liberação. Em síntese, a sublimação reorienta a satisfação para formas aceitáveis socialmente, mas mantém na consciência a necessidade de satisfação, ou seja, preserva o pensamento negativo em relação à sociedade estabelecida. Por sua vez, a "dessublimação" favorece a produção de uma "consciência feliz", ou seja, uma consciência que aceita acriticamente as mistificaçôes da realidade, na qual o real e o racional são, no limite, identificados.

Assim como essa sociedade tende a reduzir e até a absorver a oposição (a diferença qualitativa!) no âmbito da política e da cultura superior, também tende a fazê-lo na esfera instintiva.

O resultado é a atrofia dos órgãos mentais, impedindo-os de perceber as contradições e alternativas e, na única dimensão restante da racionalidade tecnológica, prevalece a Consciência Feliz (MARCUSE, 1973, p. 88).

Segundo Marcuse, tal consciência "reflete o novo conformismo, que é uma faceta da racionalidade tecnológica traduzida em comportamento social" (1973, p. 92). Pode-se inferir que é dessa forma que a indústria cultural reorienta as massas, quase não permitindo a evasão e impondo sem cessar os esquemas de seu comportamento, fazendo com que as pessoas aceitem o mundo tal como ele é preparado por ela.

Desse modo, é promovida a constituição de uma subjetividade cristalizada pela aceitação e, concomitantemente, pelo combate ao negativo, ao diferente, ou seja, uma subjetividade debilitada em sua autonomia. Justamente essa é a finalidade última da indústria cultural, a saber, tentar manter os sujeitos como escravos de seus ditames.

\section{CONSIDERAÇÕES FINAIS}

O desenvolvimento histórico do homem na modernidade lhe imputa um processo de alheamento de si e do outro. O que implica a intensificação de sua inserção no mundo do capital e da mercadoria. Com o desenvolvimento da ciência, a técnica passa a exercer absoluto poder sobre a sociedade.

Tal processo se acirra com o Iluminismo e sua promessa de vida melhor e de felicidade mediada pelo progresso científico. Paradoxalmente, o que deveria trazer libertação resulta em dominação, dependência e inconsciência. O objetivo era acabar com o mito, mas a ele retorna, isto é, o que deveria ser desmistificação converte-se em nova mistificação.

A indústria cultural insufla-lhe idéias e valores que são aceitos sem objeção, sem análise e sem serem confrontados com os reais interesses do homem enquanto ser genérico. O homem se reduz ao indivíduo burguês, extremamente identificado com as mercadorias, com o consumo. Este não percebe que vive uma realidade produzida e reafirmada como "o progresso da vida humana", mas se resume a um grande mercado, cujas características e dimensões morais, éticas, políticas não existem; a existência é subordinada aos interesses do capital. 


\section{Referências}

ADORNO, Theodor W. Sociologia. São Paulo: Ática, 1993.

CROCHIK, José Leon. O desencanto sedutor: a ideologia da racionalidade tecnológica. Inter-ação, Goiânia, v. 28, n. 1, p.15-35, jan./jun. 2003.

DESCARTES. O discurso do método. In: . Os pensadores. São Paulo: Abril Cultural, 1962, p. 37-79.

FREUD, Sigmund. O mal-estar na civilização. In: . Obras psicológicas. Rio de Janeiro: Imago, v. 21, 1996a, p. 73-148.

. Formulações sobre os dois princípios do funcionamento mental. In: Obras psicológicas. Rio de Janeiro: Imago, v. 12, 1996b, p. 81-154.

Além do princípio do prazer. In: . Obras psicológicas. Rio de Janeiro: Imago, v. 18, 1996c, p. 17-80.

HOBSBAWM, Eric. A era das revoluções. Trad.: Maria Tereza Lopes Teixeira e Marcos Penchel. São Paulo: Paz e Terra, 2004a. . A era do capital. São Paulo: Paz e Terra, 2004b.

HORKHEIMER, Max. Eclipse da razão. São Paulo: Centauro, 2000.

HORKHEIMER. Max; ADORNO, Theodor W. Dialética do esclarecimento: fragmentos filosóficos. Trad.: Guido Antonio de Almeida, Rio de Janeiro: J. Zahar, 1985. ; . Temas básicos da sociologia. Trad.: Álvaro Cabral. São Paulo: Cultrix e Edusp,

1973.

IANNI, Octavio. Teorias da globalização. Rio de Janeiro: Civilização Brasileira, 1995.

MARCUSE, Herbert. A ideologia da sociedade industrial. Rio de Janeiro: Zahar, 1973. Eros e civilização: uma interpretação filosófica do pensamento de Freud. Trad.: Álvaro Cabral. 8. ed. Rio de Janeiro: LTC, 1975.

MARX, Karl. Manuscritos econômicos-filosóficos. Trad.: Artur Morão. Lisboa: Edições 70, 1989. . O capital: crítica da economia política. São Paulo: Abril Cultural, 1983 (Os pensadores).

MATOS, Olgária C. F. A escola de Frankfurt: luzes e sombras do iluminismo. São Paulo: Moderna, 1993. 


\section{M. Bastos}

\section{Subjectivity and objectification: an introductory analysis}

\section{Abstract}

The historical context of modernity weaves new dimensions of the constitution of men and society. The moment brings in its essence the emblematic mark of the rising of the subject, which tends to stimulate the possibility of emancipation and elucidation. However, as the illuminist promise of autonomy cannot be accomplished, the awareness movement results in alienation of human consciousness, which leads to a receding subjectivity and consequently, a fragile one. An individual based on self-reasoning that tends to thoughtlessness and automatism, to a state of res, of thing, ends up being consolidated. This paper aims to provide a preliminary analysis of the elements that make possible this kind of subjectivity.

Keywords: Subjectivity. Objectification. Consciousness.

\section{Subjectivité et chosification humaine : une étude introductive \\ Résumé}

Le contexte historique de la modernité tisse de nouvelles dimensions de la constitution de l'homme et de la société. Le moment apporte dans son sein une marque emblématique de l'élévation du sujet, lequel tend à potentialiser sa possibilité d'émancipation et d'éclaircissement. Entretemps, la promesse illuministe d'autonomie ne se réalise pas, le mouvement de l'éclaircissement résulte en aliénation de la conscience humaine, concrétisant une subjectivité que régresse et ainsi, fragilisée. Se consolide alors un sujet avec une raison individuelle qui tend à l'irréflexion et à l automatisme, à un état de res, de chose. Ce travail vise une analyse préliminaire des éléments qui rendent possible telle chosification de la subjectivité.

Mots clefs: Subjectivité. Chosification. Conscience.

\section{Subjetividad y cosificación humana: un estudio introductorio}

\section{Resumen}

El contexto histórico de la modernidad teje nuevas dimensiones de la constitución del hombre y de la sociedad. El momento trae en su vientre la marca emblemática de la elevación del sujeto, el cual tiende a potencializar su posibilidad de emancipación y aclaramiento. Sin embargo, la promesa iluminista de autonomía no se cumple, el movimiento de aclaramiento redunda en alienación de la consciencia humana, concretizando una subjetividad regredida y, por eso, fragilizada. Se consolida un sujeto de la razón individual que tiende a irreflexión y al automatismo, a un estado de res, de cosa. Este trabajo visa desarrollar un analisis preliminar de los elementos que posibilitan tal cosificación.

Palabras-clave: Subjetividad. Cosificación. Consciencia. 